\title{
Hydrogenated Borophene Shows Catalytic Activity as Solid Acid
}

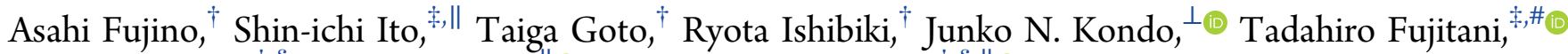 \\ Junji Nakamura, ${ }^{\ddagger},{ }^{\S}$ Hideo Hosono, ${ }^{\circledR \odot}$ and Takahiro Kondo*, ${ }^{*}, \S, \|_{\odot}$ \\ ${ }^{\dagger}$ Graduate School of Pure and Applied Sciences, ${ }^{\star}$ Department of Materials Science, Faculty of Pure and Applied Sciences, and \\ ${ }^{\S}$ Tsukuba Research Center for Energy Materials Science, University of Tsukuba, 1-1-1, Tennodai, Tsukuba, Ibaraki 305-8573, Japan \\ "Materials Research Center for Element Strategy, Tokyo Institute of Technology, Yokohama, Kanagawa 226-8503, Japan \\ ${ }^{\perp}$ Institute of Innovative Research, Tokyo Institute of Technology, 4259 Nagatsuta, Yokohama, Kanagawa 226-8503, Japan \\ "Interdisciplinary Research Center, National Institute of Advanced Industrial Science and Technology, 1-1-1 Higashi, Tsukuba, \\ Ibaraki 305-8565, Japan
}

\section{Supporting Information}

ABSTRACT: Hydrogen boride (HB) or hydrogenated borophene sheets are recently realized two-dimensional materials that are composed of only two light elements, boron and hydrogen. However, their catalytic activity has not been experimentally analyzed. Herein, we report the catalytic activity of HB sheets in ethanol reforming. HB sheets catalyze the conversion of ethanol to ethylene and water above $493 \mathrm{~K}$ with high selectivity, independent of the contact time, and with an apparent activation energy of $102.8 \pm 5.5 \mathrm{~kJ} / \mathrm{mol}$. Hence, we identify that HB sheets act as solid-acid catalysts.

\section{INTRODUCTION}

Two-dimensional (2D) materials have great potential for application as catalysts because of their unique properties such as large surface areas and novel electronic states. ${ }^{1,2}$ Among $2 \mathrm{D}$ materials, boron-related materials have unique characteristics different from other $2 \mathrm{D}$ materials in that they have polymorphisms, ${ }^{3-5}$ i.e., there are a wide variety of stable $2 \mathrm{D}$ phases owing to the capability to form multicenter bonding configurations of boron. ${ }^{6}$ Single monoatomic 2D boron (borophene) layers have been fabricated on solid surfaces with several different stable structures, ${ }^{7}$ which is consistent with theoretical predictions regarding polymorphs of borophene. $^{8-10}$

These polymorph characteristics of $2 \mathrm{D}$ boron sheets provide an opportunity to optimize the catalytic performance by tuning the bonding configurations of the $2 \mathrm{D}$ boron network. For example, it has been recently reported that boron nanosheets exfoliated from bulk boron exhibited efficient electrocatalytic performance for $\mathrm{NH}_{3}$ formation from $\mathrm{N}_{2}$ in neutral media. ${ }^{11}$ Recent experimental and theoretical studies also showed that $\alpha$-phase molybdenum diboride $\left(\alpha-\mathrm{MoB}_{2}\right)$ comprising noble metal-free borophene subunits exhibits superefficient electrocatalytic properties for the hydrogen evolution reaction. ${ }^{12}$ What we expect here is that these observed catalytic performances will be further improved by optimizing the electronic structure of $2 \mathrm{D}$ boron sheets through the adjusting of the $2 \mathrm{D}$ boron bonding-network configurations as well as conventional doping and/or composite formation.

This catalyst design concept with an attractive polymorph $2 \mathrm{D}$ boron character can be extended to hydrogenated borophene (referred to as borophane) sheets, since the polymorph $2 \mathrm{D}$ phases of borophane have been theoretically predicted. ${ }^{5}$ However, the catalytic performance of borophane has not been experimentally analyzed, to the best of our knowledge.

Recently, we revealed that a type of borophane sheet, the hydrogen boride (HB) sheet, with an empirical formula of $\mathrm{H}_{1} \mathrm{~B}_{1}$, can be experimentally prepared by exfoliation and complete ion-exchange between protons and magnesium cations in magnesium diboride $\left(\mathrm{MgB}_{2}\right)$, with an average yield of $42.3 \%$ at room temperature. ${ }^{13}$ Our extensive analysis revealed that the prepared $\mathrm{HB}$ sheets did not show any longrange order but have a local structure of a hexagonal boron network with bridge hydrogens, as shown in Figure $1 \mathrm{a} .{ }^{13} \mathrm{~A}$ recent analysis using soft X-ray absorption and emission spectroscopy at the B K-shell also supports this view and shows the semimetallicity of $\mathrm{HB}$ sheets. ${ }^{14} \mathrm{HB}$ sheets release their hydrogen content as $\mathrm{H}_{2}$ molecules in a wide temperature range from 423 to $1473 \mathrm{~K}^{13}$ The hydrogen in $\mathrm{HB}$ has a character of protons $\left(\mathrm{H}^{+}\right)$rather than that of hydrides $\left(\mathrm{H}^{-}\right)$, based on the B 1s core-level states, density functional theory calculations, and the Hammett acidity function $\left(H_{0}\right.$, acid strength); the $H_{0}$ of $\mathrm{HB}$ sheets is below 1.5 and above $0.43 .{ }^{13}$ From this viewpoint, we can regard $\mathrm{HB}$ sheets as proton-covered $2 \mathrm{D}$ boron sheets. We can thus expect that HB sheets would exhibit intriguing catalytic performance for proton-related chemical reactions and would be used as theoretically predicted hydrogen-storage materials ${ }^{15,16}$ and in batteries. ${ }^{17-19}$ In this work, we therefore examined the catalytic activity of $\mathrm{HB}$ sheets in the ethanol-reforming reaction to clarify their acid/base catalytic property and performance.

Received: July 2, 2019

Accepted: August 1, 2019

Published: August 15, 2019 


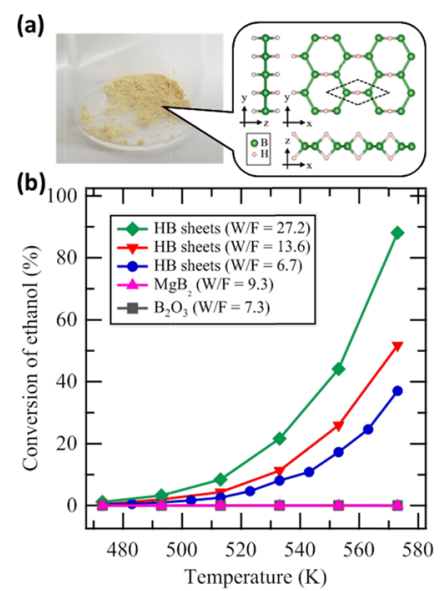

Figure 1. (a) Photograph of $\mathrm{HB}$ sheets in powder form and schematic of the proposed local structure. ${ }^{13}$ (b) Conversion of ethanol vs temperature. The results for $\mathrm{HB}, \mathrm{B}_{2} \mathrm{O}_{3}$, and $\mathrm{MgB}_{2}$ are plotted for various $\mathrm{W} / \mathrm{F}(\mathrm{g} \cdot \mathrm{min} / \mathrm{mmol})$ conditions (contact time, weight of the catalyst divided by the flow rate of $\left.\mathrm{C}_{2} \mathrm{H}_{5} \mathrm{OH}\right)$.

\section{RESULTS AND DISCUSSION}

Figure $1 \mathrm{~b}$ shows the conversion of ethanol as a function of temperature at various $W / F$ conditions (contact time); $W / F$ $(\mathrm{g} \cdot \mathrm{min} / \mathrm{mmol})$ is the weight of the catalyst $(\mathrm{g})$ divided by the flow rate of $\mathrm{C}_{2} \mathrm{H}_{5} \mathrm{OH}(\mathrm{mmol} / \mathrm{min})$. The conversion was estimated from the total amount of hydrocarbons in the product (see the details in the Supporting Information). In every case, we heated the sample at $573 \mathrm{~K}$ under Ar flow for 1 $\mathrm{h}$ prior to the measurement. It is clear that $\mathrm{HB}$ sheets exhibit distinct ethanol conversion, whereas $\mathrm{MgB}_{2}$ (starting material for the synthesis of $\mathrm{HB}$ ) and $\mathrm{B}_{2} \mathrm{O}_{3}$ (product obtained by heating $\mathrm{B}(\mathrm{OH})_{3}$, which is a byproduct in $\mathrm{HB}$ sheet synthesis, to $400 \mathrm{~K}$ or more) exhibit no ethanol conversion. The conversion by the $\mathrm{HB}$ sheets increases with an increase in $W /$ $F$; it is $90 \%$ at $573 \mathrm{~K}$ and $W / F=27.2 \mathrm{~g} \cdot \mathrm{min} / \mathrm{mmol}$. The conversion remains constant for a long period. As an example, the conversion at $573 \mathrm{~K}$ and $W / F=7.3 \mathrm{~g} \cdot \mathrm{min} / \mathrm{mmol}$ as a function of the reaction time is shown by blue circles in Figure 2a. In this case, the total amount of hydrocarbons at $13.4 \mathrm{~h}$ is $3.2 \mathrm{mmol}$, which is approximately half of the total $\mathrm{B}$ atom numbers of used $\mathrm{HB}$ sheets. We also estimated the conversion from the ethanol consumption, as shown by the red triangles in Figure 2a (see the details in the Supporting Information). The conversion calculated from the hydrocarbon production and that from the ethanol consumption are almost the same at $12 \mathrm{~h}$ (approximately 40\%), indicating that the product hydrocarbon does not accumulate on the catalyst HB sheets during the steady-state catalytic process. These results hence indicate that the HB sheets catalytically convert ethanol. It is notable that pretreatment heating at $573 \mathrm{~K}$ causes inevitable hydrogen release from $\mathrm{HB}$ as $\mathrm{H}_{2} \cdot{ }^{13}$ The maximum amount of released hydrogen at $573 \mathrm{~K}$ could be estimated as approximately 33-50 atom $\%$ of $\mathrm{HB}$ based on the thermal desorption spectroscopy (TDS) results $^{13}$ (see the details in the Supporting Information). It is implying that the stoichiometry of the $\mathrm{HB}$ sheets showing the catalytic activity was not $\mathrm{H}: \mathrm{B}=1: 1$ but approximately $\mathrm{H}: \mathrm{B}=1: 2.5 \pm 0.5$ (if they were forming a uniform structure).

We detected the catalytically converted products using gas chromatography; they were predominantly ethylene and water, together with other products such as methane, ethane, and a (a)
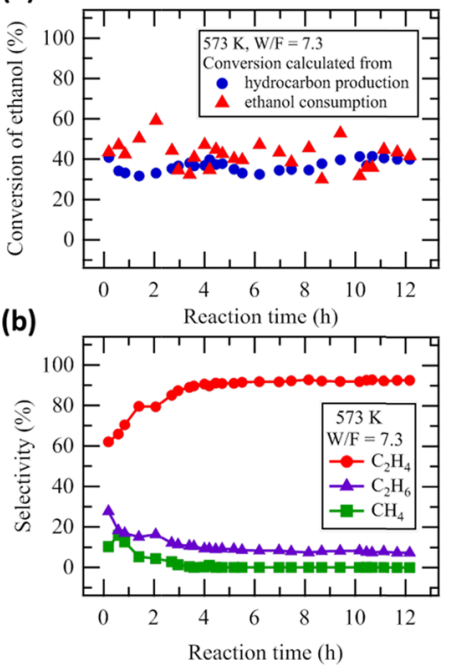

Figure 2. (a) Conversion of ethanol on $\mathrm{HB}$ sheets as a function of reaction time at $573 \mathrm{~K}$ and $W / F=7.3 \mathrm{~g} \cdot \mathrm{min} / \mathrm{mmol}$, estimated from hydrocarbon production (blue circles) and ethanol consumption (red triangles). (b) Selectivity vs reaction time.

trace amount of acetaldehyde, as shown in Figure $2 \mathrm{~b}$. The selectivity of ethylene was relatively low at the early stage, i.e., $0-4 \mathrm{~h}$ reaction time; this could be ascribed to the presence of surplus hydrogen in $\mathrm{HB}$ compared with the amount of hydrogen at the steady-state in $\mathrm{HB}$ at $573 \mathrm{~K}$ (details in the Supporting Information). We observed the same characteristics at all of the measured temperatures and $W / F$ conditions, as shown in Figure $3 \mathrm{a}, \mathrm{b}$; i.e., $\mathrm{C}_{2} \mathrm{H}_{4}$ was always the main
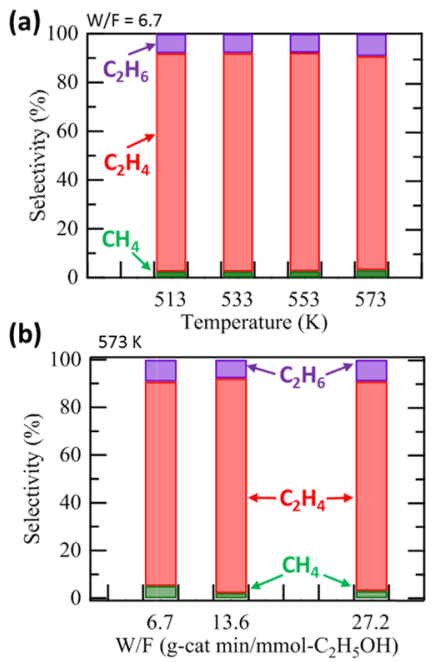

Figure 3. (a) Selectivity of ethanol reforming by $\mathrm{HB}$ as a function of temperature at $W / F=6.7 \mathrm{~g} \cdot \mathrm{min} / \mathrm{mmol}$. (b) Selectivity of ethanol reforming by $\mathrm{HB}$ at $573 \mathrm{~K}$ and $W / F=6.7,13.6$, and $27.2 \mathrm{~g} \cdot \mathrm{min} /$ mmol.

product, and the selectivity for the obtained total hydrocarbon was almost the same. These results indicate that the major catalytic reaction of ethanol reforming by the $\mathrm{HB}$ sheets is the dehydration reaction: $\mathrm{C}_{2} \mathrm{H}_{5} \mathrm{OH} \rightarrow \mathrm{C}_{2} \mathrm{H}_{4}+\mathrm{H}_{2} \mathrm{O}$. It is known that if a catalyst promotes the dehydration reaction of ethanol, it is a solid-acid; however, if the dehydrogenation reaction occurs, producing an acetaldehyde, the catalyst is a base catalyst. The HB sheets are therefore solid-acid catalysts, which 
is consistent with the $H_{0}$ of the $\mathrm{HB}$ sheets (below 1.5 and above 0.43$)^{13}$ in terms of the acidic character.

Figure 4 shows the Arrhenius plot of the ethanol-reforming reaction rate $k$, which was calculated by assuming a first-order

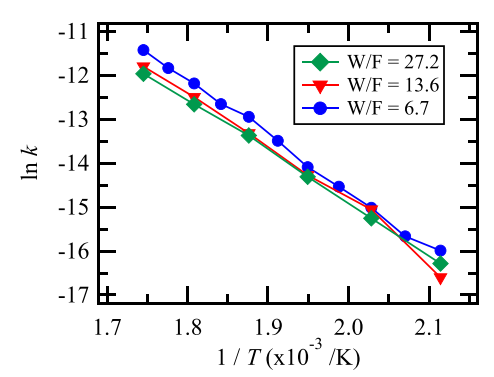

Figure 4. Arrhenius plot of the ethanol-reforming reaction rate $(k)$ in the presence of $\mathrm{HB}$ sheets for $W / F=27.2,13.6$, and $6.7 \mathrm{~g} \cdot \mathrm{min} / \mathrm{mmol}$.

reaction, as $k=\left(\mathrm{C}_{2} \mathrm{H}_{5} \mathrm{OH}\right.$ conversion [\%] $) / 100 \times\left(\mathrm{C}_{2} \mathrm{H}_{5} \mathrm{OH}\right.$ flux $[\mathrm{mol} / \mathrm{s}]) /(\mathrm{HB}$ amount $[\mathrm{mol}])$, for the results under various $W / F$ conditions with the $\mathrm{HB}$ sheets. As the obtained linear lines are almost the same and they are independent of $W / F$, the reaction can be (at least apparently) considered a first-order reaction. To determine the exact reaction order and mechanism, further kinetic analysis is required. From the slope and the section, the apparent activation energy $E_{\mathrm{a}}$ and preexponential factor $A$ were estimated to be $102.8 \pm 5.5 \mathrm{~kJ} / \mathrm{mol}$ and $3.5 \times 10^{4} \mathrm{~s}^{-1}$, respectively. The derived $E_{\mathrm{a}}$ is comparable to the reported activation energies for the catalytic dehydration of ethanol over $\mathrm{Al}_{2} \mathrm{O}_{3}(53-155 \mathrm{~kJ} / \mathrm{mol}),{ }^{20,21}$ the Lewis acidic $\mathrm{Zr}$ KIT-6 catalyst $(79 \mathrm{~kJ} / \mathrm{mol}),{ }^{22}$ silica-alumina $(125.5 \mathrm{~kJ} /$ $\mathrm{mol}){ }^{23}$ and microporous Fe-ZSM-5 (137.7-271.1 kJ/mol). ${ }^{24}$ The formation rate of ethylene on our $\mathrm{HB}$ catalyst at $573 \mathrm{~K}$ and $W / F=7.3 \mathrm{~g} \cdot \mathrm{min} / \mathrm{mmol}$ was $2.4 \pm 0.1 \mathrm{mmol} / \mathrm{g} \cdot \mathrm{h}$ (Figure 2 ). Although this is not the formation rate at the optimal catalytic condition, here, we compare it with those of the other reported catalysts. Chen and co-workers reported that the formation rate of ethylene from ethanol using the commercial SynDol $\left(\mathrm{Al}_{2} \mathrm{O}_{3}-\mathrm{MgO} / \mathrm{SiO}_{2}\right)$ catalyst was $7.8 \mathrm{mmol} / \mathrm{g} \cdot \mathrm{h}$ at 591 $\mathrm{K}$, with a weight hourly space velocity (WHSV) of $0.23 \mathrm{~h}^{-1}$ in a fixed-bed reactor (this value is calculated using the reported yield of the ethylene, which is $0.22 \mathrm{~g} /$ gcat $\cdot \mathrm{h}){ }^{25}$ They also reported a higher formation rate of $535 \mathrm{mmol} / \mathrm{g} \cdot \mathrm{h}$ on $\mathrm{Ti} / \gamma$ $\mathrm{Al}_{2} \mathrm{O}_{3}$ at $633 \mathrm{~K}$ and WHSV of $26 \mathrm{~h}^{-1}$ using the microreactor (calculated using a value of $15 \mathrm{~g} / \mathrm{gcat} \cdot \mathrm{h}$ ). ${ }^{25}$ The formation rate of $\mathrm{HB}$ sheets is, thus, lower than that of the state-of-the-art catalysts but is in the same order as that of the commercial SynDol catalyst.

Finally, we herein discuss the possible reaction mechanism and active sites as well as the acid property of the HB sheets. In the case of ethanol reforming on a zeolite catalyst, ${ }^{26-32}$ diethyl ether $\left(\mathrm{C}_{2} \mathrm{H}_{5} \mathrm{OC}_{2} \mathrm{H}_{5}\right)$ is formed as a result of a two-molecule reaction. Diethyl ether then converts to ethylene at strong Brønsted acid sites. The number and the strength of strong Brønsted acid sites in the catalyst are thus reported to determine the catalytic activity for ethylene formation. Since $\mathrm{HB}$ sheets show weaker $H_{0}\left(1.5 \geq H_{0} \geq 0.43\right)^{13}$ compared with that of zeolites (e.g., $-3.0 \geq H_{0} \geq-8.2$ of H-Zeolite), ${ }^{33}$ we can expect the formation of diethyl ether rather than ethylene on HB sheets, based on the trend of zeolite. However, we observed ethylene instead of diethyl ether on the HB sheets (Figures 2 and 3). Thus, the reaction is considered to proceed as a single molecule reaction via the formation of an ethoxy
$\left(\mathrm{C}_{2} \mathrm{H}_{5} \mathrm{O}-\right)$ species rather than the two-molecule reaction via the formation of diethyl ether. Indeed, the derived apparent activation energy $(102.8 \pm 5.5 \mathrm{~kJ} / \mathrm{mol})$ from Figure 4 is similar to that for the decomposition of the ethoxy intermediate generated from ethanol on a zeolite $(122 \pm 3 \mathrm{~kJ} / \mathrm{mol}) .^{34}$ The ethoxy species can thus be formed prior to ethylene on $\mathrm{HB}$; this will be investigated using infrared spectroscopy in our future work. Concerning the active site, the bridge-type hydrogen in the HB sheets and/or terminal-type hydrogen at the edge of the $\mathrm{HB}$ sheets can be expected to act as the Brønsted acid sites. However, as described above, the stoichiometry of the $\mathrm{HB}$ sheets used in this work for the catalytic activity measurements is not $\mathrm{H}: \mathrm{B}=1: 1$ due to the inevitable hydrogen release as $\mathrm{H}_{2}$ at the pretreatment heating of $573 \mathrm{~K}$ (release as much as $33-50 \%$ of hydrogen in $\mathrm{HB}$ ). Thus, we cannot simply assign the hydrogen atoms of the outermost surface (bridge- and/or edge-type of hydrogens) of $\mathrm{HB}$ (Figure 1a) as the active sites. There is a possibility that the boron atom that does not bond with hydrogen acts as the Lewis acid site if a hydrogen vacancy is created locally and the boron atom adopts a simple $\mathrm{sp}^{2}$ bonding configuration with surrounding boron atoms (Figure 1a) without any electron in its $\mathrm{p}_{z}$ orbital. On the other hand, if the charges in the HB sheets are delocalized well to supply electrons to the $\mathrm{p}_{z}$ orbital of a bare $\mathrm{sp}^{2}$-bonded boron atom (at hydrogen vacancy), the boron atom may act as a Brønsted base, similar to the lattice oxygen in zeolite, and promote the dehydrogenation of ethoxy to form ethylene. According to our catalytic activity measurements for the $\mathrm{HB}$ sheets without pretreatment heating (Figure S4), the selectivity is different from that shown in Figure 3. This difference in selectivity can be attributed to the difference in the hydrogen amount in $\mathrm{HB}$, as in the case of the origin of the induction period shown in Figure $2 b$ (see the details in the Supporting Information). We can hence at least classify that the $\mathrm{HB}$ and heated $\mathrm{HB}$ (hydrogen-deficient-HB) have different catalytic properties (i.e., different acid sites). However, the active sites cannot be solely determined by our current experimental results. At least it should be clarified whether the hydrogen-deficient $\mathrm{HB}$ consists of a uniform stoichiometric structure or defective structure. Further investigation is thus required to determine the exact active sites of the $\mathrm{HB}$ solidacid catalyst, e.g., the careful structure characterization, infrared spectroscopy analysis with pyridine, $\mathrm{NH}_{3}$, and $\mathrm{CO}_{2}$ adsorption, and $H_{0}$ measurements with quantitative density, as a function of the pretreatment heating temperature (i.e., hydrogen amount in $\mathrm{HB}$ ).

\section{CONCLUSIONS}

We found that hydrogen boride or hydrogenated borophene sheets catalyze the conversion of ethanol to ethylene and water above $493 \mathrm{~K}$, with high selectivity, independent of the contact time, and an apparent activation energy of $102.8 \pm 5.5 \mathrm{~kJ} / \mathrm{mol}$. We hence consider hydrogenated borophene sheets to be novel, nonmetal, and two-dimensional solid-acid catalysts that have great potential for application as hydrogen-storage materials and in batteries.

\section{EXPERIMENTAL SECTION}

Materials. HB sheets were prepared using a previously reported ion-exchange method. ${ }^{13}$ Specifically, $\mathrm{MgB}_{2}$ powder (1.0 g, 99\%, Rare Metallic Co., Ltd., Tokyo, Japan) in acetonitrile $(300 \mathrm{~mL}, 99.5 \%$, Wako Pure Chemical Industries 
Ltd., Osaka, Japan) was mixed with a solution of an ionexchange resin $(60 \mathrm{~mL}$, Amberlite IR120B hydrogen form, Organo Corp., Tokyo, Japan) and acetonitrile $(200 \mathrm{~mL})$ in a Schlenk flask under a nitrogen atmosphere, where water inclusion is sensitive to the product ${ }^{35}$ and thus careful removal of water was done beforehand. This mixture was stirred using a magnetic stirrer at $400 \mathrm{rpm}$ for 2 days at room temperature. The supernatant was then kept for 1 day at $255 \mathrm{~K}$ to physically separate the byproduct $\mathrm{B}(\mathrm{OH})_{3}$. Dried $\mathrm{HB}$ sheets were prepared by heating the resulting liquid at $343 \mathrm{~K}$ while pumping with a liquid nitrogen trap. For all of the syntheses, we carefully confirmed the product by X-ray photoelectron spectroscopy to confirm the absence of $\mathrm{Mg}$ and the presence of negatively charged B without oxidized B as reported previously. ${ }^{13}$ Moreover, we recently confirmed using atomic force microscopy (AFM) that our HB sheets mostly consist of a few to several tens of layers. The details of AFM with statistical analysis will be published in our future work.

Catalytic Activity Measurements. To determine the catalytic activity, gaseous ethanol was introduced into the $\mathrm{HB}$ sheets using an argon carrier gas under atmospheric pressure in a homemade fixed-bed flow reactor. The product gas was then analyzed using a thermal conductivity detector in a gas chromatograph (GC-8A, Shimadzu, Kyoto, Japan) equipped with Molecular Sieve 5A and Porapak $Q$ at the downstream end of the reactor. The catalytic conversion was estimated from the total amount of hydrocarbon production using the following relation

ethanol conversion $(\%)=[$ (number of total carbon in

detected hydrocarbon molecules $)(\mathrm{mol} / \mathrm{min})]$

$/[$ introduced ethanol molecules $\times 2(\mathrm{~mol} / \mathrm{min})] \times 100$

As shown in Figure 2a, the conversion was also estimated from ethanol consumption as follows

$$
\begin{aligned}
& \text { ethanol conversion }(\%)=[(\text { introduced ethanol molecules } \\
& - \text { detected ethanol molecules })(\mathrm{mol} / \mathrm{min})] \\
& \quad / \text { introduced ethanol molecules }(\mathrm{mol} / \mathrm{min})] \times 100
\end{aligned}
$$

The selectivity was estimated using the following relation

$$
\begin{aligned}
& \text { selectivity of specific product }(\%) \\
& =\frac{\text { total amount of specific product }(\mathrm{mol})}{\text { total amount of products }(\mathrm{mol})} \times 100
\end{aligned}
$$

The catalytic activity was determined under various $W / F$ conditions $(\mathrm{g} \cdot \mathrm{min} / \mathrm{mmol})$, which is the weight of the catalyst (g) divided by the flow rate of $\mathrm{C}_{2} \mathrm{H}_{5} \mathrm{OH}(\mathrm{mmol} / \mathrm{min}) ; W / F$ was controlled by adjusting the flow rate of $\mathrm{C}_{2} \mathrm{H}_{5} \mathrm{OH}$ and the weight of the sample. The $W / F$ conditions used in this work are listed in Table S1.

\section{ASSOCIATED CONTENT}

\section{S Supporting Information}

The Supporting Information is available free of charge on the ACS Publications website at DOI: 10.1021/acsomega.9b02020.

Origin of the induction period, TDS, effect of water, and catalytic activity of $\mathrm{HB}$ without pretreatment heating (PDF)

\section{AUTHOR INFORMATION}

\section{Corresponding Author}

*E-mail: takahiro@ims.tsukuba.ac.jp.

ORCID

Junko N. Kondo: 0000-0002-7940-1266

Tadahiro Fujitani: 0000-0002-1225-3246

Hideo Hosono: 0000-0001-9260-6728

Takahiro Kondo: 0000-0001-8457-9387

\section{Notes}

The authors declare no competing financial interest.

\section{ACKNOWLEDGMENTS}

This work was supported by the JSPS KAKENHI nos. JP 18K18989, JP 19H05046, and JP $19 \mathrm{H} 02551$ and Murata Science Foundation, KUMAGAI, Ogasawara, and Samco foundations for the Promotion of Science \& Engineering. T.K., S.-i.I., and H.H. were supported by the MEXT Element Strategy Initiative to Form Core Research Center.

\section{REFERENCES}

(1) Wang, Y.; Mao, J.; Meng, X.; Yu, L.; Deng, D.; Bao, X. Catalysis with Two-Dimensional Materials Confining Single Atoms: Concept, Design, and Applications. Chem. Rev. 2019, 119, 1806-1854.

(2) Deng, D.; Novoselov, K. S.; Fu, Q.; Zheng, N.; Tian, Z.; Bao, X. Catalysis with Two-Dimensional Materials and Their Heterostructures. Nat. Nanotechnol. 2016, 11, 218-230.

(3) Zhang, Z.; Penev, E. S.; Yakobson, B. I. Two-Dimensional Boron: Structures, Properties and Applications. Chem. Soc. Rev. 2017, 46, 6746-6763.

(4) Kondo, T. Recent Progress in Boron Nanomaterials. Sci. Technol. Adv. Mater. 2017, 18, 780-804.

(5) Jiao, Y.; Ma, F.; Bell, L.; Bilic, A.; Du, A. Two-Dimensional Boron Hydride Sheets:High Stability, Massless Dirac Fermions, and Excellent Mechanical Properties. Angew. Chem. Int. Ed. 2016, 55, 10292-10295.

(6) Oganov, A. R.; Solozhenko, V. L. Boron: A Hunt for Superhard Polymorphs. J. Superhard Mater. 2009, 31, 285-291.

(7) Mannix, A. J.; Kiraly, B.; Hersam, M. C.; Guisinger, N. P. Synthesis and Chemistry of Elemental 2D Materials. Nat. Rev. Chem. 2017, 1, 0014.

(8) Boustani, I. New Quasi-Planar Surfaces of Bare Boron. Surf. Sci. 1997, 370, 355-363.

(9) Penev, E. S.; Bhowmick, S.; Sadrzadeh, A.; Yakobson, B. I. Polymorphism of Two-Dimensional Boron. Nano Lett. 2012, 12, 2441-2445.

(10) Wu, X.; Dai, J.; Zhao, Y.; Zhuo, Z.; Yang, J.; Zeng, X. C. TwoDimensional Boron Monolayer Sheets. ACS Nano 2012, 6, 74437453.

(11) Zhang, X.; Wu, T.; Wang, H.; Zhao, R.; Chen, H.; Wang, T.; Wei, P.; Luo, Y.; Zhang, Y.; Sun, X. Boron Nanosheet: An Elemental Two-Dimensional (2D) Material for Ambient Electrocatalytic $\mathrm{N}_{2}$-to$\mathrm{NH}_{3}$ Fixation in Neutral Media. ACS Catal. 2019, 9, 4609-4615.

(12) Chen, Y.; Yu, G.; Chen, W.; Liu, Y.; Li, G.; Zhu, P.; Tao, Q.; Li, Q.; Liu, J.; Shen, X.; et al. Highly Active, Nonprecious Electrocatalyst Comprising Borophene Subunits for the Hydrogen Evolution Reaction. J. Am. Chem. Soc. 2017, 139, 12370-12373.

(13) Nishino, H.; Fujita, T.; Cuong, N. T.; Tominaka, S.; Miyauchi, M.; Iimura, S.; Hirata, A.; Umezawa, N.; Okada, S.; Nishibori, E.; et al. Formation and Characterization of Hydrogen Boride Sheets Derived from $\mathrm{MgB}_{2}$ by Cation Exchange. J. Am. Chem. Soc. 2017, 139, 13761-13769.

(14) Tateishi, I.; Cuong, N. T.; Moura, C. A. S.; Cameau, M.; Ishibiki, R.; Fujino, A.; Okada, S.; Yamamoto, A.; Araki, M.; Ito, S.; et al. Semimetallicity of Free-Standing Hydrogenated Monolayer Boron from $\mathrm{MgB}_{2}$. Phys. Rev. Mater. 2019, 3, No. 024004. 
(15) Chen, L.; Chen, X.; Duan, C.; Huang, Y.; Zhang, Q.; Xiao, B. Reversible Hydrogen Storage in Pristine and Li Decorated 2D Boron Hydride. Phys. Chem. Chem. Phys. 2018, 20, 30304-30311.

(16) Abtew, T. A.; Shih, B. C.; Dev, P.; Crespi, V. H.; Zhang, P. Prediction of a Multicenter-Bonded Solid Boron Hydride for Hydrogen Storage. Phys. Rev. B: Condens. Matter Mater. Phys. 2011, 83, No. 094108.

(17) Makaremi, M.; Mortazavi, B.; Singh, C. V. 2D Hydrogenated Graphene-like Borophene as a High Capacity Anode Material for Improved Li/Na Ion Batteries: A First Principles Study. Mater. Today Energy 2018, 8, 22-28.

(18) Xiang, P.; Chen, X.; Xiao, B.; Wang, Z. M. Highly Flexible Hydrogen Boride Monolayers as Potassium-Ion Battery Anodes for Wearable Electronics. ACS Appl. Mater. Interfaces 2019, 11, 81158125.

(19) Shukla, V.; Araujo, R. B.; Jena, N. K.; Ahuja, R. Borophene's Tryst with Stability: Exploring 2D Hydrogen Boride as an Electrode for Rechargeable Batteries. Phys. Chem. Chem. Phys. 2018, 20, 2200822016.

(20) Bakoyannakis, D. N.; Zamboulis, D.; Stalidis, G. A.; Deliyanni, E. A. The Effect of Preparation Method on the Catalytic Activity of Amorphous Aluminas in Ethanol Dehydration. J. Chem. Technol. Biotechnol. 2001, 76, 1159-1164.

(21) Christiansen, M. A.; Mpourmpakis, G.; Vlachos, D. G. Density Functional Theory-Computed Mechanisms of Ethylene and Diethyl Ether Formation from Ethanol on $\gamma-\mathrm{Al}_{2} \mathrm{O}_{3}(100)$. ACS Catal. 2013, 3, $1965-1975$.

(22) Pan, Q.; Ramanathan, A.; Kirk Snavely, W.; Chaudhari, R. V.; Subramaniam, B. Intrinsic Kinetics of Ethanol Dehydration over Lewis Acidic Ordered Mesoporous Silicate, Zr-KIT-6. Top. Catal. 2014, 57, 1407-1411.

(23) Roca, F.; De Mourgues, L.; Trambouze, Y. Catalytic Dehydration of Ethanol over Silica-Alumina. J. Catal. 1969, 14, 107-113.

(24) Maihom, T.; Khongpracha, P.; Sirijaraensre, J.; Limtrakul, J. Mechanistic Studies on the Transformation of Ethanol into Ethene over Fe-ZSM-5 Zeolite. ChemPhysChem 2013, 14, 101-107.

(25) Chen, G.; Li, S.; Jiao, F.; Yuan, Q. Catalytic Dehydration of Bioethanol to Ethylene over $\mathrm{TiO}_{2} / \gamma-\mathrm{Al}_{2} \mathrm{O}_{3}$ Catalysts in Microchannel Reactors. Catal. Today 2007, 125, 111-119.

(26) Takahara, I.; Saito, M.; Inaba, M.; Murata, K. Dehydration of Ethanol into Ethylene over Solid Acid Catalysts. Catal. Lett. 2005, $105,249-252$.

(27) Madeira, F. F.; Gnep, N. S.; Magnoux, P.; Maury, S.; Cadran, N. Ethanol Transformation over HFAU, HBEA and HMFI Zeolites Presenting Similar Brønsted Acidity. Appl. Catal., A 2009, 367, 3946.

(28) Chiang, H.; Bhan, A. Catalytic Consequences of Hydroxyl Group Location on the Rate and Mechanism of Parallel Dehydration Reactions of Ethanol over Acidic Zeolites. J. Catal. 2010, 271, 251261.

(29) Xin, H.; Li, X.; Fang, Y.; Yi, X.; Hu, W.; Chu, Y.; Zhang, F.; Zheng, A.; Zhang, H.; Li, X. Catalytic Dehydration of Ethanol over Post-Treated ZSM-5 Zeolites. J. Catal. 2014, 312, 204-215.

(30) Kadam, S. A.; Shamzhy, M. V. IR Operando Study of Ethanol Dehydration over MFI Zeolites. Catal. Today 2018, 304, 51-57.

(31) Zhang, M.; Yu, Y. Dehydration of Ethanol to Ethylene. Ind. Eng. Chem. Res. 2013, 52, 9505-9514.

(32) Sun, J.; Wang, Y. Recent Advances in Catalytic Conversion of Ethanol to Chemicals. ACS Catal. 2014, 4, 1078-1090.

(33) Varvarin, A. M.; Khomenko, K. M.; Brei, V. V. Conversion of N-Butanol to Hydrocarbons over H-ZSM-5, H-ZSM-11, H-L and HY Zeolites. Fuel 2013, 106, 617-620.

(34) Kondo, J. N.; Yamazaki, H.; Osuga, R.; Yokoi, T.; Tatsumi, T. Mechanism of Decomposition of Surface Ethoxy Species to Ethene and Acidic OH Groups on H-ZSM-5. J. Phys. Chem. Lett. 2015, 6, 2243-2246.

(35) Nishino, H.; Fujita, T.; Yamamoto, A.; Fujimori, T.; Fujino, A.; Ito, S.; Nakamura, J.; Hosono, H.; Kondo, T. Formation Mechanism of Boron-Based Nanosheet through the Reaction of $\mathrm{MgB}_{2}$ with Water. J. Phys. Chem. C 2017, 121, 10587-10593.

\section{NOTE ADDED AFTER ASAP PUBLICATION}

This paper published ASAP on August 15, 2019 with an inaccurate equation due to production error. The corrected version reposted to the Web on August 19, 2019. 